\title{
Desenvolvimento e avaliação de Jogos Educativos Digitais (JED) sobre a temática água: um estudo de caso utilizando a ferramenta GameMaker: Studio
}

Thayanna Pedroza, Universidade Católica de Brasília, thayannamp@gmail.com

Thiago Ferreira, Universidade Federal da Integração Latino-Americana, thiagovf21@gmail.com

Maria das Graças Cleophas, Universidade Federal da Integração Latino-Americana, maria.porto@unila.edu.br

Resumo: Este artigo apresenta um estudo de caso que tem como objeto de análise o desenvolvimento e avaliação de dois Jogos Educativos Digitais (JED), especialmente produzidos para promover o letramento científico e tecnológico por meio do enlace com o enfoque CTSA (Ciência, Tecnologia, Sociedade e Ambiente) sobre uma temática transversal e de ampla importância mundial: a água. Os jogos foram utilizados e avaliados por um grupo de 80 discentes em formação inicial em educação científica. Os resultados mostram que ambos os jogos permitiram que os discentes fizessem relações entre os diferentes conteúdos inseridos nos jogos e situações vivenciadas em seu cotidiano, dando indícios de que as resoluções dos problemas abordados nos jogos, por meio dos desafios, foram transferidas para um contexto externo (real).

Palavras-chave: Jogo Educativo Digital (JED), Ensino de ciências, Água.

Development and evaluation of Digital Educational Games (DEG) on the topic of water: a case study using the GameMaker: Studio tool

Abstract: This article presents a case study on the development and evaluation of two Digital Educational Games (DEG) specially produced to promote scientific and technological literacy related to the STSE (Science, Technology, Society and Environment) approach to a cross-cutting issue of global importance: water. The games were used and evaluated by a group of 80 students in initial training in scientific education. The results show that both games allowed students to establish connections between the different contents included in the games and situations experienced in their daily life, indicating that the solutions of the problems addressed in the games through the challenges were transferred to an external (real) context, thus promoting changes in subjects' stances towards the problems related to the water.

Keywords: Digital Educational Game (DEG), Science Teaching, Water.

\section{Jogos Educativos Digitais (JED) e a temática água sob o enfoque CTSA (Ciência, Tecnologia, Sociedade e Ambiente)}

O presente artigo descreve e avalia o processo de elaboração de dois Jogos Educativos Digitais (JED) desenvolvidos para contribuir com o processo de ensino e aprendizagem da temática água. Para Prensky (2012), os JED possuem muitas características que são atrativas para o ambiente educacional, porque contribuem com a motivação, curiosidade, desafio, treinamento, prática e feedback, permitindo assim, a aprendizagem por meio dos erros e de forma contextualizada. Assim, a inserção dos JED nos contextos educacionais faz emergir "formas de pensamento não lineares que envolvem negociações e abrem caminhos para diferentes estilos cognitivos e emocionais" (ALVES, 2007, p. 151).

Comenta-se, com frequência, sobre a importância da construção de um ambiente educacional que preze pela discussão de temas que favoreçam diálogos plurais sobre Ciência, Tecnologia, Sociedade e Meio Ambiente, pois eles são responsáveis, em grande 
parte, por contribuir com a formação de sujeitos críticos e alfabetizados cientificamente e tecnologicamente. Igualmente, no tocante à alfabetização científica, Sasseron e Carvalho (2008) defendem que ela auxilia os sujeitos "na construção de uma consciência mais crítica em relação ao mundo que o cerca" (p. 334). Para tanto, é fundamental escolher assuntos que não sejam estanques, tal como a temática água, pois ela consiste de uma seara que pode fomentar diferentes tipos de problematizações quando conjecturadas ao enfoque CTSA, com vistas à promoção de uma alfabetização científica e tecnológica, preparando, assim, os sujeitos "para uma cidadania dentro da sociedade do conhecimento" (NUNES; DANTAS, 2012, p. 89) e, particularmente, da informação.

Há várias formas de promover a alfabetização científica e tecnológica nos diferentes tipos de ambientes educacionais. Uma delas, certamente, pode ser defendida por meio da construção e aplicação de JED sobre a água, pois consiste de um tema que permite aos sujeitos agir, compreender e tomar decisões perante as mudanças da sociedade e do ambiente ao seu redor. Assim, a água pode ser considerada um dos eixos basilares imbuídos no tema transversal denominado Educação Ambiental. Devido ao seu caráter multidimensional, as atividades que têm como cerne as discussões e/ou criações de projetos que discutam de forma holística os problemas relacionados à água se tornam potencialmente favoráveis para contribuir com a alfabetização tecnológica e científica dos sujeitos.

Assim, visando a problematização de aspectos relacionados à água, propomos a construção de dois JED, e sua posterior avaliação, sendo que um apresenta curiosidades e situações do cotidiano, e o outro se estrutura em forma de desafios, ou seja, perguntas e respostas que objetivam a melhoria do conhecimento dos alunos sobre uma temática tão comum, mas ainda pouco explorada cientificamente e tecnologicamente em sua totalidade, nos mais diferentes níveis educacionais.

Ainda convém lembrar que um ensino de ciências pautado em um enfoque CTSA que vise favorecer o letramento científico e tecnológico dos alunos requer uma elaboração pedagógica com elevado planejamento por parte do professor, pois, deste modo, se torna possível contribuir com mudanças de atitudes dos alunos sobre a importância dos temas transversais que são essenciais para a formação do seu caráter social. Logo, os JED surgem como promissores no processo de repaginação das estratégias didáticometodológicas e devem estar presentes no processo de formação docente inicial e continuada, pois podem colaborar com a ampliação de distintos saberes necessários para a educação dos indivíduos no século XXI.

A utilização dos JED proporciona ao aluno a chance de compreender temas transversais de modo mais atrativo, dinâmico, prazeroso e reflexivo, auxiliando, portanto, a construção de sua cidadania. Os JED integram uma classe de jogos denominados "sérios", pois apresentam um propósito útil para a formação do sujeito, ao agregar aspectos educativos a um contexto de diversão, promovendo, assim, o desenvolvimento de diferentes habilidades cognitivas. Para Gee (2005), os JED utilizam conteúdos que se integram com domínios semióticos que podem promovem aprendizagens.

Visando a conexão de domínios semióticos ao conteúdo água, por meio da construção de JED, buscou-se edificar uma abordagem metodológica diferenciada que favorecesse distintas habilidades e competências para dentro e fora da sala de aula, pois o uso da temática água tende a fortalecer conceitos e aproximar os alunos dos problemas ambientais existentes na contemporaneidade, mostrando-lhes possíveis caminhos para contorná-los. Para tanto, é fundamental que tenhamos sujeitos críticos, reflexivos e, sobretudo, suscetíveis à mudança de posturas frente aos problemas relacionados à água, tais como sua escassez, poluição, mau uso, etc. 
Os dois JED que serão descritos e avaliados neste artigo foram elaborados por meio de um software gratuito disponível no site yoyo games, chamado GameMaker: studio. Este software é de fácil utilização e possui uma programação já preestabelecida, permitindo, assim, a criação de jogos de qualidade sem requerer domínio mais elevado sobre linguagens de programação.

\section{Metodologia}

A pesquisa foi realizada com 80 discentes dos cursos de Licenciatura em Ciências da Natureza e Química da Universidade Federal da Integração Latino-Americana, localizada em Foz do Iguaçu - PR/Brasil. Foi construída uma Sequência Didática (SD) a partir de discussões pautadas em uma abordagem CTSA para (re)construir e/ou fortalecer aprendizagens sobre a temática água, pois, conforme já mencionamos, consiste de uma temática de ampla importância mundial e que ainda necessita de estratégias didáticas que fomentem discussões que promovam uma educação voltada a incentivar a tomada de decisões dos sujeitos em relação aos seus inúmeros problemas. Portanto, dentro deste enfoque CTSA, os dois jogos elaborados aproximam o cotidiano dos alunos dos vários subtemas relacionados com diferentes aspectos econômicos, sociais, ambientais e políticos sobre a água, por meio de uma contextualização que interliga os seus conteúdos científicos, proporcionando, assim, o desenvolvimento de habilidades sociocognitivas nos alunos. Vale destacar que existem poucos JED sobre o tema em questão relatados na literatura. Isto demonstra que a água consiste de um assunto que apresenta elevado potencial para fomentar discussões interdisciplinares e contextualizadas, especialmente no que tange à construção dos JED sob uma perspectiva alfabetizadora de ciência e tecnologia.

Após todo o processo técnico de desenvolvimento dos jogos, iniciou-se, em sala de aula, um debate sobre a temática 'água' pautado em um enfoque CTSA visando uma formação mais crítica e reflexiva dos alunos sobre os problemas relacionados à agua no que se refere à sua preservação e, sobretudo, à necessidade de conscientização sobre o uso racional da água. Em seguida, os discentes tiveram contato com os jogos. Nesta etapa, os alunos puderam jogar e avaliar a proposta didática em questão.

O presente trabalho possui uma abordagem de caráter qualitativo-descritivo, baseada em um estudo de caso (YIN, 2014). O caso aqui retratado consiste na avaliação dos jogos elaborados pelos sujeitos participantes desta pesquisa. Visando uma melhor sistematização, o caso foi dividido em dois minicasos, pois um jogo apresenta características de uma aprendizagem guiada por perguntas (Dino's adventure), e o outro apresenta elementos que incentivam uma aprendizagem baseada em tarefas (Water Nymph).

Como instrumento de coleta de dados, foi utilizado um questionário semiestruturado, elaborado com o auxílio do Google Forms e disponibilizado eletronicamente por link via e-mail para os discentes em formação inicial. Os dados foram categorizados e analisados com o auxílio do software NVivo 11. Cabe ressaltar que tal software consiste em uma ferramenta projetada para dar robustez ao tratamento de dados qualitativos, ajudando, assim, a organizar, analisar e estruturar dados coletados em uma pesquisa.

\section{Resultados e Discussões}

\subsection{Sobre o desenvolvimento dos Jogos Educativos Digitais (JED)}


Os jogos foram produzidos com o software GameMaker: Studio, utilizando uma linguagem própria de programação, onde os comandos são preestabelecidos, facilitando, deste modo, o seu manuseio. O software conta também com um editor básico de imagens, onde os sprites e backgroups dos dois jogos foram editados. Segundo Tarouco et al. (2005, p. 4), "o desenvolvimento de jogos educacionais envolve a escolha de um tema, público alvo e objetivos". Logo, as perguntas e curiosidades foram baseadas em conteúdos curriculares sobre ciências naturais relacionados a todos os níveis da educação básica que estão imbuídos nas diretrizes conceituais propostas pelos Parâmetros Curriculares Nacionais (PCN). De acordo com McGonigal (2012), todos os jogos, independentemente de diferenças entre gêneros e complexidades tecnológicas, compartilham de quatro características, que são: metas, regras, sistema de feedback e participação voluntária. Para Mattar (2010), o grande desafio de um designer de jogos é produzir jogos divertidos que gerem, ao mesmo tempo, reflexão e senso crítico. Assim, torna-se possível a construção de estratégias didático-metodológicas baseadas em JED que contribuam com o processo de alfabetização científica e tecnológica sobre temas que requerem amplo debate, tal como a temática água.

Nesse sentido, buscou-se a construção de jogos que mantivessem em equilíbrio os aspectos lúdicos inerentes à sua estrutura com os elementos necessários para a promoção de aprendizagens. Para tanto, foi preciso tomar como 'guia' os itens descritos na Tabela 1 que foi proposta por Bedwell (2012) e citada por Bertin et al. (2015, p. 03), que nortearam o processo de idealização e construção dos jogos propostos, incluindo, assim, a inserção dos objetivos didáticos e os atributos imprescindíveis para o desenvolvimento de jogos que proporcionem aos sujeitos uma reflexão e, sobretudo, o afloramento do senso crítico tão basilar para o favorecimento de uma "educação para a água" (BACCI; PATACA, 2008, p. 211).

Tabela 1. Elementos significativos para o aprendizado.

$\begin{array}{ll}\text { Atributos } & \text { Definição } \\ \text { Adaptação } & \text { Nível de dificuldade se ajusta ao nível de habilidade do jogador } \\ \text { Avaliação } & \text { A medida da realização dentro do jogo } \\ \text { Desafio } & \text { Quantidade ideal de dificuldade } \\ \text { Conflito } & \text { Interações diretas, indiretas, violentas ou não violentas } \\ \text { Controle } & \text { Poder ou influência sobre os elementos do jogo } \\ \text { Fantasia } & \text { Ambientes, cenários ou personagens inusitados } \\ \text { Interação } & \text { Pode ser com o jogo, com outros jogadores ou com o grupo } \\ \text { Idioma/comunicação } & \text { Regras específicas de comunicação (verbal ou textual) do jogo } \\ \text { Localização } & \text { Mundo físico ou virtual do jogo } \\ \text { Mistério } & \text { Provoca a curiosidade, novidade, surpresas, complexidade e ideias } \\ \text { Peças ou jogadores } & \text { Os objetos ou pessoas que são incluídos no cenário ou na narrativa do jogo } \\ \text { Progresso } & \text { Como o jogador progride em direção aos objetivos do jogo } \\ \text { Surpresa } & \text { Elementos aleatórios não conhecidos pelos jogadores } \\ \text { Representação } & \text { Característica que faz com que o jogo pareça psicologicamente real } \\ \text { Regras/Metas } & \text { Regras estabelecidas no jogo para atingir o objetivo } \\ \text { Segurança } & \text { Liberação de ações e consequências } \\ \text { Fonte: Extraído de Bertin et al. (2015, p. 03). }\end{array}$

O primeiro jogo, chamado de Dino's Adventure, aborda temas sobre o ciclo da água no planeta - aspectos teóricos e metodológicos e a água: aspectos históricos, geográficos e científicos. Ele é inspirado nos jogos $O$ bom dinossauro: o desafio, Disney Crossy e Dibble Dash. Em suma, baseia-se em um personagem controlado pelo jogador através das setas do teclado, onde o jogador precisar superar alguns desafios para voltar para sua casa. Nestes desafios, o jogador tem acesso a algumas curiosidades e relatos sobre diferentes aspectos atrelados à água, tais como a sua história e os seus ciclos. Acreditamos que o contato do jogador com as distintas informações auxilia na transposição dos conhecimentos advindos do jogo para o seu contexto social, ou seja, 
permite que o jogador haja dentro do universo do jogo e também para fora dele, por meio de um condicionamento que ultrapassa a esfera do jogo e que contribui com uma transformação social.

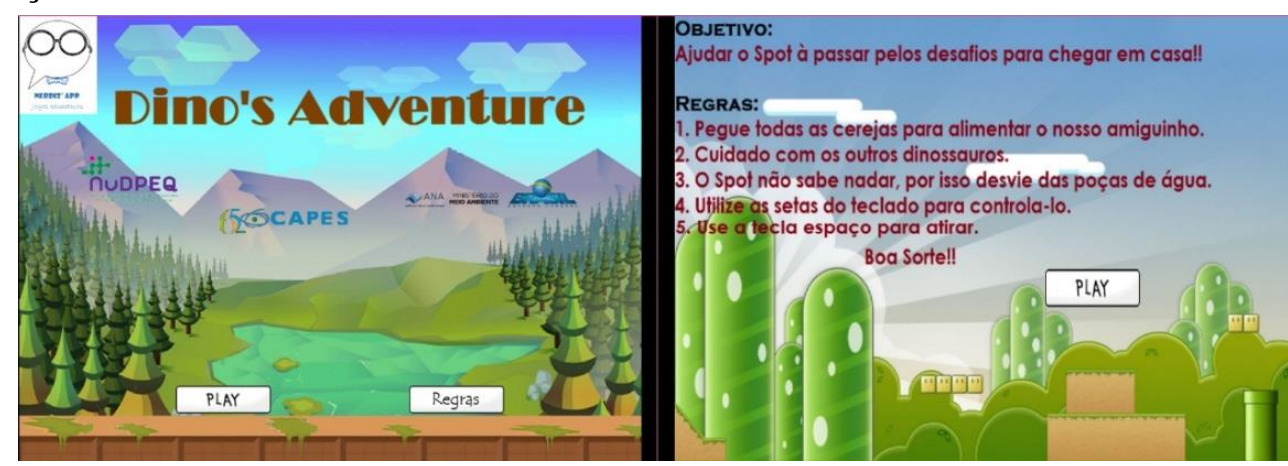

Figura 1: Tela Inicial do jogo Dino's Adventure e suas regras.

Fonte: Autores, 2017.

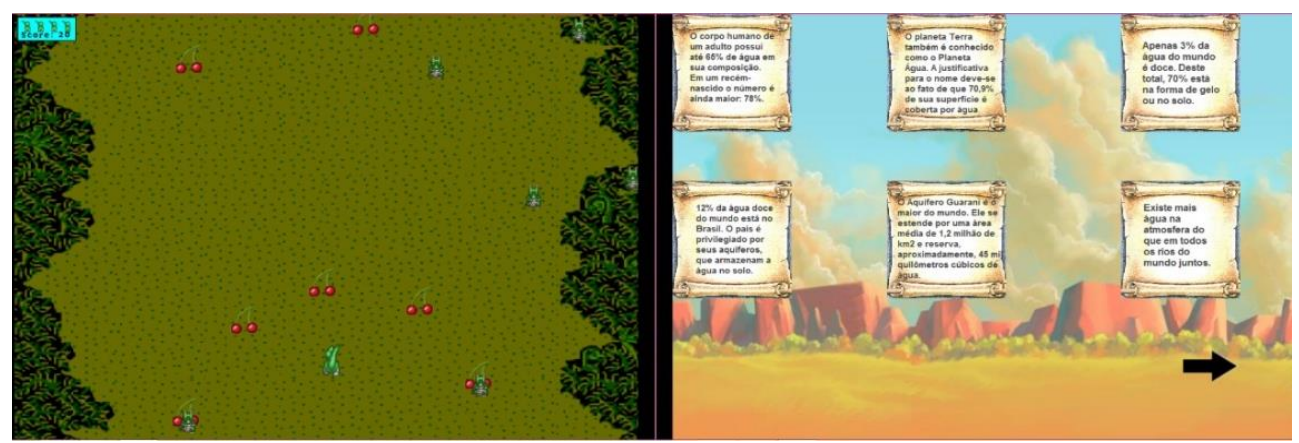

Figura 2: Fase 1 do jogo Dino's Adventure.

Fonte: Autores, 2017.

Já o segundo jogo, intitulado Water Nymph, traz em seu enredo assuntos sobre Educação Ambiental, sustentabilidade e participação social. O jogo é baseado nos games Super Mário, Rayman Adventure e Nob's World. Também é constituído por um personagem controlado pelo jogador através das setas do teclado do computador ou notebook, cabendo ao jogador superar alguns desafios para salvar o planeta, que teve suas águas poluídas. O jogador, durante o jogo, que é baseado em tarefas, tem acesso a algumas dicas que são fornecidas no seu decorrer, auxiliando, assim, que ele responda às perguntas, para, então, ele ter condições para passar para a próxima tarefa e, ao final, enfrentar o Senhor Sujão (chefão), que está causando toda a poluição. Ao longo dos desafios propostos, as tarefas que compõem as fases vão ficando cada vez mais difíceis, testando, deste modo, o nível de conhecimento do jogador sobre diferentes temas vinculados à água.

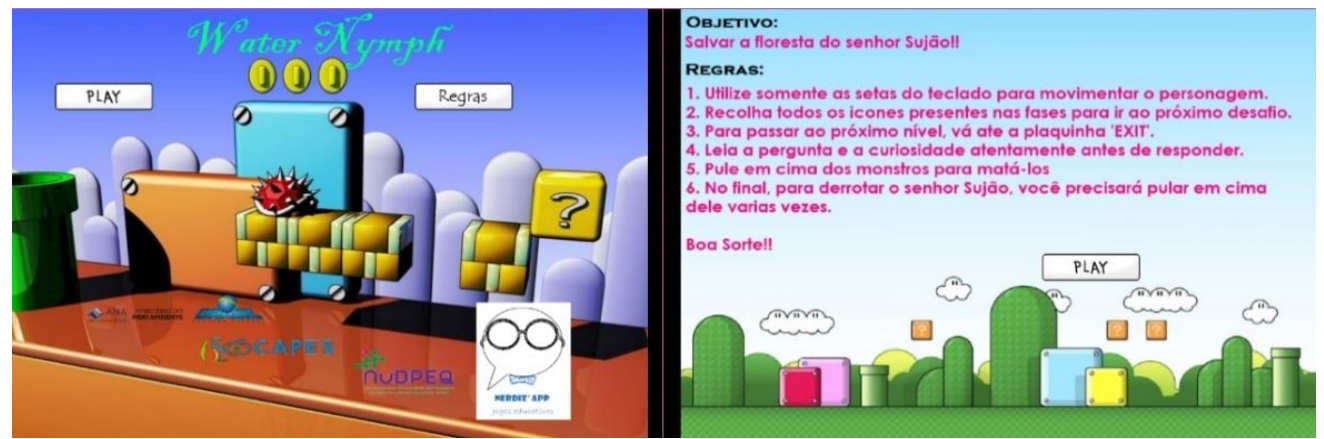

Figura 3: Tela Inicial do jogo Water Nymph e suas regras. Fonte: Autores, 2017. 

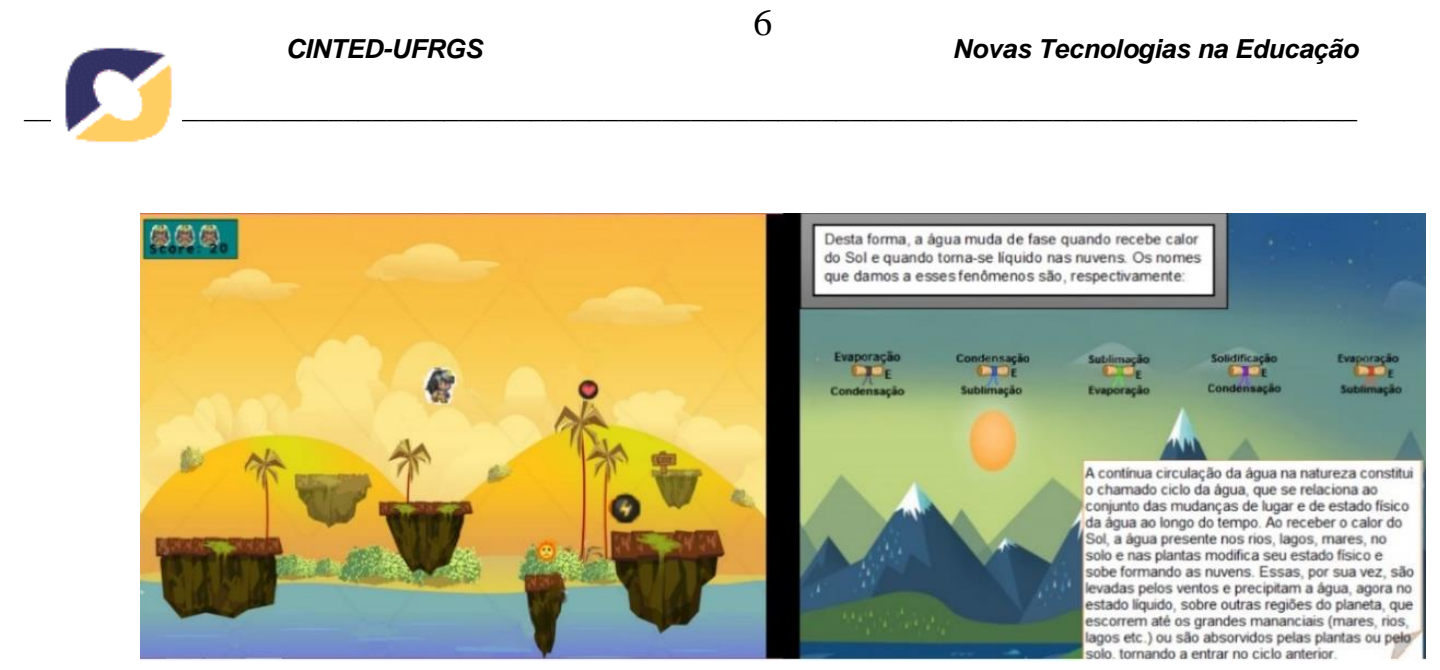

Figura 4: Fase 1 do jogo Water Nymph. Fonte: Autores, 2017.

Os jogos estão disponíveis para jogar online, sendo possível seu acesso somente após cadastro gratuito no site denominado www.empoderagua.com.br. É importante frisar que ambos os jogos primaram por abarcar diferentes subtemas relacionados ao enfoque CTSA em sua narrativa, sendo estes, considerados valorosos para uma educação para a água e que podem ser utilizados por alunos de todas as idades e níveis educacionais.

\subsection{Avaliação dos jogos desenvolvidos com o auxílio do NVivo 11}

Conforme mencionamos, solicitamos a 80 discentes dos cursos de licenciatura em Ciências da Natureza e Química que respondessem à seguinte questão: 'Qual a análise você faz sobre o Jogo 1 (Dino's Adventure) e sobre o Jogo 2 (Water Nymph)? Descreva sua opinião sincera sobre os dois jogos'. Com a utilização no NVivo 11, calculamos a frequência das palavras mais recorrentes durante o processo de resposta ao questionamento citado acima. Com essa frequência, foi possível determinar quais são as palavras que formaram o núcleo semântico (categorias) que emergiram por meio da similaridade de palavras e que serviram para balizar a avaliação dos jogos em função das categorias levantadas. Com as categorias identificadas, é possível realizar a análise de Cluster, que permite determinar o grau de concordância entre as respostas obtidas e o grau de correlação entre os nós (VALDEMOROS-SAN-EMETERIO et al., 2011). As Tabelas 2 e 3 exibem as dez palavras mais mencionadas nas respostas atribuídas pelos discentes para os dois jogos.

Tabela 2 - Frequência das dez palavras mais utilizadas pelos alunos entrevistados, referentes ao Jogo 1.

\begin{tabular}{|c|c|c|c|c|c|}
\hline & A & B & c & D & \\
\hline & Palavra & Extensāo & Contagem & Percentual ponderado (\%) & Palavras similares \\
\hline 1 & jogo & 4 & 320 & 004 & jogo, jogos \\
\hline 2 & água & 4 & 183 & 002 & água \\
\hline 3 & informaçōes & 11 & 94 & 001 & informaçōes \\
\hline 4 & forma & 5 & 49 & 001 & forma, formas \\
\hline 5 & dinossauros & 11 & 48 & 001 & dinossauro, dinossauros \\
\hline 6 & dino & 4 & 45 & 001 & dino, dinos \\
\hline 7 & tempo & 5 & 43 & 001 & tempo \\
\hline 8 & fase & 4 & 42 & 001 & fase, fases \\
\hline 9 & interessante & 12 & 42 & 001 & interessante, interessantes \\
\hline 10 & pouco & 5 & 37 & 000 & pouco \\
\hline
\end{tabular}

Fonte: Dados da pesquisa.

Tabela 3 - Frequência das dez palavras mais utilizadas pelos alunos entrevistados, referentes ao Jogo 2. 


\begin{tabular}{|c|c|c|c|c|c|}
\hline & A & B & c & D & E \\
\hline & Palavra & Extensāo & Contagem & Percentual ponderado (\%) & Palavras similares \\
\hline 1 & jogo & 4 & 123 & 004 & jogo. jogos \\
\hline 2 & água & 4 & 33 & 001 & água, águas \\
\hline 3 & fase & 4 & 33 & 001 & fase, fases \\
\hline 4 & informaçōes & 11 & 23 & 001 & informaçōes \\
\hline 5 & perguntas & 9 & 20 & 001 & pergunta, perguntas \\
\hline 6 & interessante & 12 & 19 & 001 & interessante, interessantes \\
\hline 7 & passar & 6 & 16 & 001 & passar \\
\hline 8 & responder & 9 & 14 & 000 & responde, responder \\
\hline 9 & jogador & 7 & 14 & 000 & jogador, jogadores \\
\hline 10 & questāo & 7 & 14 & 000 & questāo \\
\hline
\end{tabular}

Fonte: Dados da pesquisa.

A análise exploratória por meio do NVivo nos forneceu os nós em cluster que indicam o agrupamento de palavras por similaridade, ou seja, os "nós funcionam como variáveis que reúnem informações descritivas do texto, possibilitando a identificação de tendências" (ALVES et al., 2015, p. 125). A Figura 5 mostra que as respostas dos sujeitos entrevistados culminaram em 04 (quatro) tendências (identificadas durante a análise dos dados através de um processo de codificação inicial realizado com auxílio do software), que foram denominadas de categorias de análise: Facilidade, Dificuldade, Aprendizagem e Ensino.

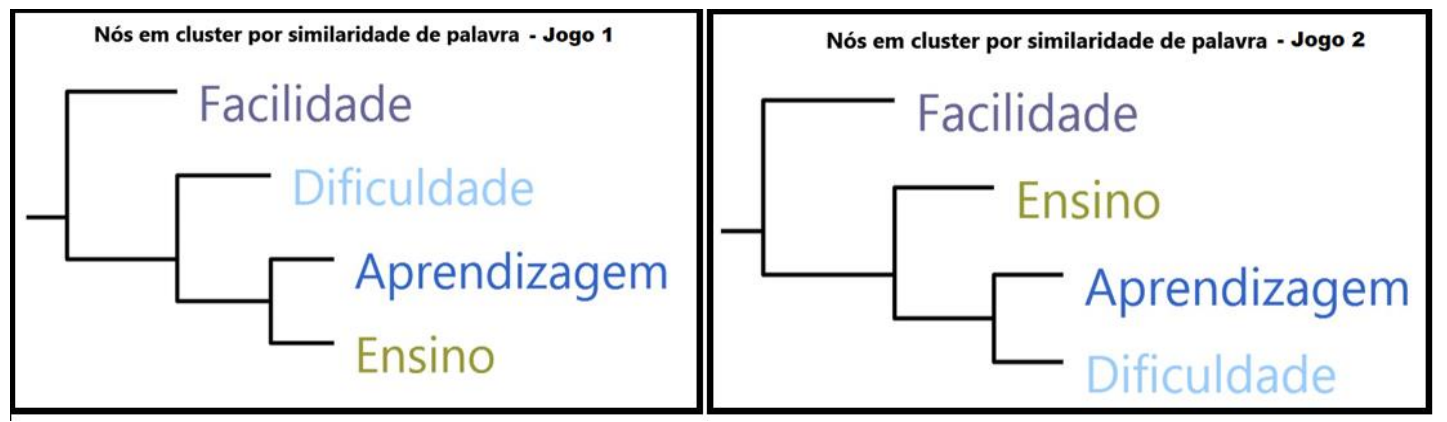

Figura 5: Diagrama de nós por similaridade de palavra.

Fonte: Dados da pesquisa.

Podemos observar, com a ajuda do Gráfico 1, que a avaliação dos dois jogos pelos discentes revelou resultados diferentes. O Jogo 2 foi melhor avaliado pelos alunos em todas as categorias, quando comparado ao Jogo 1, mostrando, deste modo, ser um jogo que promoveu uma melhor aprendizagem sobre os temas abordados no jogo, ou seja, em seu processo de elaboração, o Jogo 2, certamente, conseguiu atingir um maior número de atributos que foram significativos para o aprendizado do sujeito-jogador (Tabela 1), contribuindo, assim, com o desenvolvimento de habilidades cognitivas sobre a temática água.
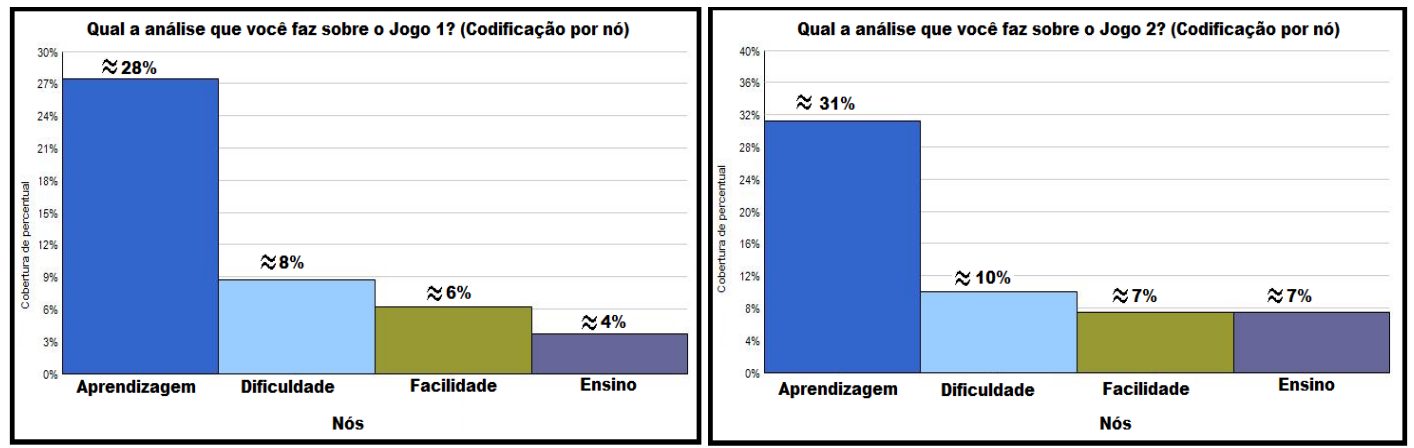

Gráfico 1: Porcentagem relacionada a cada categoria de análise. Fonte: Dados da pesquisa. 
Em complemento à Figura 5 e ao Gráfico 1, foi elaborado um quadro contendo as categorias de análise e exemplos de fragmentos textuais referentes à cobertura interna dos nós em cada categoria por jogo analisado. Assim, com a análise do Quadro 1, percebemos que os fragmentos textuais corroboram o Jogo 2 como sendo o mais eficaz sob o ponto de vista cognitivo dos alunos, pois envolve a solução de problemas, fornece feedback imediato sobre os resultados, contribuindo, assim, para a aprendizagem dos sujeitos, além de motivar o aluno para refletir sobre os problemas ambientais e sociais atrelados à água. Acreditamos que o fato de o Jogo 2 apresentar melhores resultados, em comparação ao Jogo 1, não inviabilizou o Jogo 1 em atingir a sua tarefa no que diz respeito a uma transposição do agir no jogo para fora dele, ou seja, pelo treinamento que o jogo promoveu sobre assuntos relacionados à água. Seguramente, ambos os jogos contribuíram na transformação social dos sujeitos em relação a uma prática reflexiva em seu cotidiano no tangente à água e, também, numa integração mobilizadora de distintos conhecimentos necessários para tomar decisões impostas nos jogos, visando a resolução dos problemas inseridos neles. Neste viés, Freire Pinto e Cleophas (2017) defendem que os "diferentes saberes disciplinares devem dialogar entre si, para promover aprendizagens que prezem pelo não esfacelamento da compreensão sobre a água” (p. 21).

Quadro 1 - Os nós e suas coberturas para o Jogo 1 e Jogo 2.

\begin{tabular}{|c|c|c|}
\hline $\begin{array}{l}\text { Nós (categorias } \\
\text { de análise) }\end{array}$ & $\begin{array}{l}\text { Cobertura por nós - Jogo } 1 \text { (Exemplo de } \\
\text { fragmento de texto codificado neste nó } \\
\text { extraído da opinião do discente) }\end{array}$ & $\begin{array}{l}\text { Cobertura por nós - Jogo } 2 \text { (Exemplo de } \\
\text { fragmento de texto codificado neste nó } \\
\text { extraído da opinião do discente) } \\
\end{array}$ \\
\hline Aprendizagem & $\begin{array}{l}\text { É um jogo que nos ajuda a persistir a resolver } \\
\text { um problema. Além de divertido, nos } \\
\text { transmite um aprendizado simbólico sobre } \\
\text { um determinado assunto. }\end{array}$ & $\begin{array}{l}\text { O jogo } 2 \text { em minha visão é mais interessante e } \\
\text { divertido, pois tem a finalidade de retirar os } \\
\text { produtos tóxicos do meio ambiente e do mar. } \mathrm{E} \\
\text { entre as fases você responde perguntas fáceis, } \\
\text { mas muito importantes. Gostei mais desse do } \\
\text { que do primeiro jogo. E as perguntas são sobre } \\
\text { o que aprendemos na escola, tipo uma revisão. }\end{array}$ \\
\hline Dificuldade & $\begin{array}{l}\text { Apesar de ser um pouco difícil de jogar, } \\
\text { durante o jogo aparecem textos relacionados } \\
\text { à água no Brasil e em outros lugares, nos } \\
\text { fazendo pensar na importância que a água } \\
\text { tem. }\end{array}$ & $\begin{array}{l}\text { Não consegui passar da segunda fase. A } \\
\text { primeira questão que eu resolvi é muito bem } \\
\text { elaborada e além disso dá uma explicação } \\
\text { depois. O jogo, tirando a parte das perguntas, é } \\
\text { difícil. }\end{array}$ \\
\hline Facilidade & $\begin{array}{l}\text { Joguinho simples e fácil. Ideal para o } \\
\text { aprendizado sobre a água, especialmente para } \\
\text { crianças menores, ensina divertindo. }\end{array}$ & $\begin{array}{l}\text { O jogo } 2 \text { achei bem melhor, mais dinâmico e } \\
\text { divertido. A proposta de fazer um Quiz após a } \\
\text { conclusão da fase foi muito bem pensada, as } \\
\text { questões são fáceis e passam a proposta } \\
\text { planejada, além de incentivar a jogar mais para } \\
\text { saber qual é a próxima questão, como é a } \\
\text { próxima fase. Acredito que, se fosse uma } \\
\text { criança jogando, sentiria essa vontade de } \\
\text { jogar mais e mais para sanar essa curiosidade e, } \\
\text { consequentemente, aprender. }\end{array}$ \\
\hline Ensino & $\begin{array}{l}\text { O jogo é uma grande ferramenta de ensino } \\
\text { sobre a água, com bastante foco nas } \\
\text { informações apresentadas. }\end{array}$ & $\begin{array}{l}\text { Um jogo legal, que, sobretudo, pelo que eu } \\
\text { entendi, nos ensina sobre as mudanças de } \\
\text { estado físico da água. Muito interessante, e } \\
\text { legal. Jogamos e aprendemos. }\end{array}$ \\
\hline
\end{tabular}

Fonte: Dados da pesquisa.

\section{Considerações finais}

Atualmente, em pleno século XXI, há a necessidade da criação de novas formas de engajar os jovens durante o seu processo de aprendizagem, visando, assim, promover habilidades que são imprescindíveis na formação de cidadãos críticos, reflexivos e alfabetizados cientificamente e tecnologicamente. A partir desta perspectiva, podemos considerar que os JED desenvolvidos e analisados nesta pesquisa, foram estimuladores e 
potencializadores do desenvolvimento de competências voltadas para uma educação para a água.

A construção de estratégias didático-metodológicas baseadas no uso dos JED demonstrou ser uma alternativa eficaz na promoção de discussões sobre temáticas transversais. Os jogos desenvolvidos e aplicados demonstraram potencial como ferramentas pedagógicas utilizáveis em diversas áreas do conhecimento científico, pois contribuíram para a contextualização e integração da temática água em diferentes dimensões, tais como política, social, ambiental, econômica, etc. Conforme mencionado anteriormente, os jogos foram elaborados com o apoio do software GameMaker: Studio. Contudo, mesmo sendo uma ferramenta intuitiva e completa de criação de jogos, é necessário que o utilizador possua algumas habilidades técnicas de nível moderado, porém, é extremamente viável, sob o ponto de vista de execução, que professores possam aprender a manusear o software e desenvolver (de modo isolado ou em parceria com os seus alunos) projetos baseados em jogos.

De acordo com o que foi exposto e exemplificados pelos fragmentos de textos extraídos das opiniões atribuídas dos discentes sobre os jogos, é possível concluir que o Jogo 2 foi melhor avaliado pelos alunos em relação as categorias de análise atribuídas. Isto mostra que, provavelmente, este jogo foi mais eficaz em educar para a temática água, auxiliando assim, os sujeitos a transferir as aprendizagens obtidas por meio do jogo para um contexto real, pois favoreceu conflitos de natureza social, teórica, científica, etc., que podem ter influenciado mudanças nas posturas dos alunos frente às questões ambientais relacionadas à água - ou seja, os desafios inseridos no jogo requereram atitudes dos alunos-jogadores que podem ter acarretado ações que foram transferidas do universo do jogo (virtual) para o cotidiano dos alunos (real), mostrando, assim, que o jogo pode condicionar e contribuir com o processo de transformação social.

Em suma, podemos, portanto, afirmar que ambos os jogos, tendo como abordagem principal a água, podem ser utilizados como ferramentas pedagógicas na revisão de diferentes conteúdos atrelados ao tema, em diferentes abordagens problematizadoras, na possibilidade de construção de conhecimentos de natureza multi, inter e transdisciplinares, no favorecimento do letramento científico e tecnológico, como etapa de uma atividade 'gamificada', entre outras aplicações de caráter didático-metodológicas. Por fim, com os JED produzidos demonstraram-se viáveis pedagogicamente para a promoção da alfabetização científica e tecnológica em confluência com o enfoque CTSA.

\section{Agradecimentos}

À agência de fomento à pesquisa Capes e ao Núcleo de Desenvolvimento de Pesquisas em Ensino de Química/Ciências (NuDPEQ) da Universidade Federal da Integração Latino-Americana (UNILA).

\section{Referências}

ALVES, D.; FIGUEIREDO FILHO, D.; HENRIQUE, A. "O Poderoso NVivo: uma introdução a partir da análise de conteúdo". Revista Política Hoje, $2^{a}$ ed., v. 24, p. 119$134,2015$.

ALVES, L. R. G. Nativos Digitais: Games, Comunidades e Aprendizagens. In: MORAES, U. C. (Org.). Tecnologia Educacional e Aprendizagem: o uso dos recursos digitais. Livro Pronto: São Paulo, 2007, p. 233-251. 
BACCI, D.; PATACA, E. M. Educação para a água. Estudos avançados, v. 22, n. 63, p. 211-226, 2008.

BEDWELL, W. L. et al. Toward a Taxonomy Linking Game Attributes to Learning: An Empirical Study. Simulation \& Gaming, Orlando, v. 43, p. 729-760, 2012.

BERTIN, R.; LIMA, M. F. W. P.; WEBBER, C. G. Desenvolvendo jogos educacionais por meio de softwares de autoria. Revista Novas Tecnologias na Educação, v. 13, n. 1, 2015.

FREIRE PINTO, L. J.; CLEOPHAS, M. G. Adaptação do Arco de Maguerez como metodologia problematizadora na promoção de uma educação voltada para a água. Educação Ambiental em Ação, n. 60, ano XVI, p. 1-23, 2017.

GEE, J. P. Good video games good learning. Phi Kappa Phi Forum, v. 85, n. 2, p. 1-13, 2005.

MATTAR, J. Games em educação: como os nativos digitais aprendem. São Paulo: Pearson Prentice Hall, 2010, p. 208.

MCGONIGAL, J. A Realidade em Jogo. Tradução de Eduardo Rieche. Rio de Janeiro: BestSeller, 2012, p. 378.

NUNES, A. O.; DANTAS, J. M. As relações ciência-tecnologia-sociedade-ambiente (CTSA) e as atitudes dos licenciandos em química. Educación Química, v. 23, n. 1, p. 85-90, 2012.

PRENSKY, M. Aprendizagem baseada em jogos digitais. São Paulo: SENAC, 2012. p. 575.

SASSERON, L. H.; CARVALHO, A. M. P. Almejando a alfabetização científica no ensino fundamental: a proposição e a procura de indicadores do processo. Investigações em Ensino de Ciências, v. 13, n. 3, p. 333-352, 2008.

TAROUCO, L. M. R.; KONRATH, M. L. P.; GRANDO, A. R. S. O aluno como coconstrutor e desenvolvedor de jogos educacionais. Revista Novas Tecnologias na Educação, v. 3, n. 2, p. 1-8, 2005.

VALDEMOROS-SAN-EMETERIO, M. A.; PONDE-DE-LEÓN-ELIZONDO, A.; SANZ-ARAZURI, E. Fundamentos en el manejo del NVivo 9 como herramienta al servicio de estudios cualitativos. Contextos Educativos, v. 14, p. 11-29, 2011.

YIN, R. K. Case Study Research Design and Methods. Thousand Oaks, CA: Sage, 2014, p. 282. 